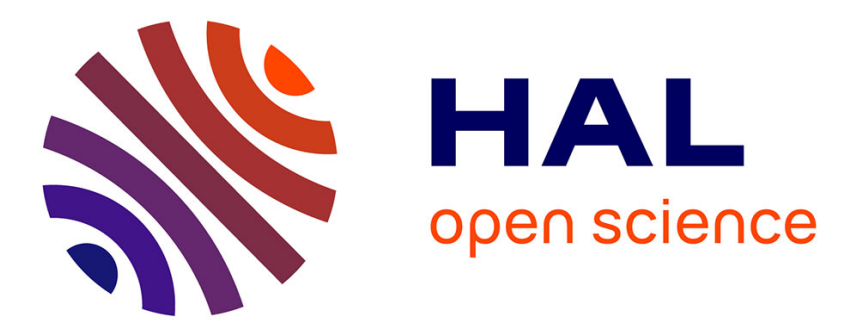

\title{
Immiscible polymer blends of semicrystalline biocompatible components: thermal properties and phase morphology analysis of PLLA/PCL blends
}

Ramiro Dell'Erba, Gabriel Groeninckx, Giovanni Maglio, Mario Malinconico, Anna Migliozzi

\section{To cite this version:}

Ramiro Dell'Erba, Gabriel Groeninckx, Giovanni Maglio, Mario Malinconico, Anna Migliozzi. Immiscible polymer blends of semicrystalline biocompatible components: thermal properties and phase morphology analysis of PLLA/PCL blends. Polymers, 2001. hal-01998591

\section{HAL Id: hal-01998591 \\ https://hal.science/hal-01998591}

Submitted on 29 Jan 2019

HAL is a multi-disciplinary open access archive for the deposit and dissemination of scientific research documents, whether they are published or not. The documents may come from teaching and research institutions in France or abroad, or from public or private research centers.
L'archive ouverte pluridisciplinaire HAL, est destinée au dépôt et à la diffusion de documents scientifiques de niveau recherche, publiés ou non, émanant des établissements d'enseignement et de recherche français ou étrangers, des laboratoires publics ou privés. 


\section{ENEA}

Italian National Agency for New Technologies, Energy and Sustainable Economic Development

http://www.enea.it/en

http://robotica.casaccia.enea.it/index.php?lang=en

This paper is a pre-print. The final paper is available on:

Polymer "Immiscible polymer blends of semicrystalline biocompatible components: thermal properties and phase morphology analysis of PLLA/PCL blends". R. dell'Erba, A.. Migliozzi, et al. 


\title{
Immiscible polymer blends of semicrystalline biocompatible components: thermal properties and phase morphology analysis of PLLA/PCL blends
}

\author{
Ramiro Dell'Erba ${ }^{\mathrm{a}}$, Gabriel Groeninckx ${ }^{\mathrm{b}}$, Giovanni Maglio ${ }^{\mathrm{c}, *}$, \\ Mario Malinconico ${ }^{\mathrm{a}}$, Anna Migliozzi ${ }^{\mathrm{c}}$ \\ astituto di Ricerca e Tecnologia delle Materie Plastiche, CNR, Via Toiano 6, I-80072 Arco Felice, Naples, Italy \\ ${ }^{\mathrm{b}}$ Katholieke Universiteit Leuven, Afd. Polymeerchemie, Celestijnenlaan 200 F, B-3001, Heverlee, Belgium \\ ${ }^{\mathrm{c}}$ Dipartimento di Chimica, Università di Napoli “Federico II", Complesso Universitario di Monte S. Angelo, Via Cinthia, I-80126 Naples, Italy
}

Received 7 February 2001; received in revised form 6 April 2001; accepted 11 April 2001

\begin{abstract}
Immiscible binary blends of poly(L,L-lactide) (PLLA), and poly( $\varepsilon$-caprolactone) (PCL), with 90/10, 80/20 and 70/30 wt\% compositions, as well as ternary PLLA/PCL blends containing $0.5-5 \mathrm{wt} \%$ of a triblock PLLA/PCL/PLLA copolymer, were obtained by melt mixing using a twin screw extruder. Optical microscopy investigation of binary blends revealed the immiscibility of the components. The thermal behaviour of the blends was investigated by DSC and DMTA and compared with that of pure PLLA. The PLLA crystallization rate was enhanced in the presence of PCL domains. Morphological analysis of the cryofractured and etched-smoothed surfaces was carried out by SEM on both binary and ternary blends. A dimensional analysis of the PCL domains in binary and ternary blends was also performed in order to evaluate the influence of the presence of the triblock copolymer on the dispersion mode of PCL in the PLLA matrix. (C) 2001 Elsevier Science Ltd. All rights reserved.
\end{abstract}

Keywords: Immiscible blends; Poly(L,L-lactide); Poly( $\varepsilon$-caprolactone)

\section{Introduction}

Polymer melt-blending is one of the most fascinating and fast growing chapters of polymer science and is an efficient way to generate new high performance materials, as demonstrated by the large number of versatile blends introduced on the market and of patents on polymer blends registered annually $[1,2]$.

In the last few years, much attention has been focused on blends of biocompatible and biodegradable polymers in view of their biomedical applications. Poly(L-lactide) (PLLA) has been intensively studied and widely used for such applications because of its high biocompatibility and good biodegradability [3-5]. Blends of PLLA with more flexible biocompatible polymers, such as $\operatorname{poly}(\varepsilon$-caprolactone) (PCL), have been developed and investigated $[6,7]$ in order to improve certain mechanical properties of PLLA, such as impact strength. PLLA/PCL blends have attracted great interest as temporary absorbable implants, but they suffer from poor mechanical properties due to the macrophase separation of the two immiscible components and to

\footnotetext{
* Corresponding author. Tel.: +390-81-674-013; fax: +390-81-674-090
}

E-mail address: maglio@chemistry.unina.it (G. Maglio). the poor adhesion between the phases. It is well known that the mechanical properties of immiscible blends are strongly dependent on their morphologies and, therefore, the control of the morphology of an immiscible polymer melt is of vital importance for the tailoring of the final properties of the product $[8,9]$. In general, the morphology results from the complex thermomechanical history experienced by the different constituents during processing. Studies performed by several authors on this topic show that during the melt processing of polymer blends, the final size, shape and distribution of the dispersed phase are determined by a variety of parameters such as the composition, viscosity ratio, shear rate/shear stress, elasticity ratio and interfacial tension among the component polymers and processing conditions, such as time and temperature of mixing, rotation speed of rotor and type of mixing [9]. Moreover, it is widely reported that well-defined copolymers can act as emulsifying agents in immiscible polymer blends [10-12]. They are able to reduce the 'coalescence effect' by lowering the interfacial tension between the blends components and may lead to a well dispersed morphology. It is generally accepted that using diblock copolymers whose chemical nature is identical to that of the main components, the length of the blocks should exceed that of the homopolymers. In the case of 
triblock or multiblock copolymers, it has been recently shown that reptation at the interface of the multiple blocks is the mechanism through which emulsification can occur, leading to interface stabilization even when the $M_{\mathrm{n}}$ of blocks is lower than that of the parent homopolymers [13]. Computer simulation methods $[14,15]$ demonstrated that the addition of an $\mathrm{A}-\mathrm{B}-\mathrm{A}$ triblock copolymer in immiscible blends of $\mathrm{A}$ and $\mathrm{B}$ homopolymers leads to smaller domain size in the dispersed phase $\mathrm{B}$ with respect to that obtained by using a A-B diblock copolymer. It was also found that in the situation described above, an A-B-A copolymer is a better interfacial agent than a B-A-B copolymer with the same molecular weight [14].

In this paper, we report on the thermal properties and phase morphology development occurring in PLLA/PCL blends when a high efficiency extruder is used. The morphology of the blends investigated is also compared with that of the corresponding blends prepared by means of a mono-axial extruder, described in a previous paper [16]. Moreover, the influence of a triblock PLLA-PCL-PLLA copolymer of controlled architecture on blend morphology has been also investigated.

\section{Experimental}

\subsection{Materials}

PLLA $\left(M_{n}=100 \mathrm{kDa}\right.$, Resomer), PCL $\left(M_{n}=55 \mathrm{KDa}\right.$, Solvay), $\alpha, \omega$-dihydroxy-poly $(\varepsilon$-caprolactone) (PCL-OH, $M_{n}=10 \mathrm{kDa}$, Aldrich) and stannous 2-ethylhexanoate (Sigma) were used as received. Size exclusion chromatography (SEC) measurements yielded $M_{\mathrm{n}}$ values of 63 and $74 \mathrm{kDa}$ for PLLA and PCL, respectively. L-Lactide (L-LA, Aldrich) was repeatedly recrystallized from anhydrous ethyl acetate before use. The synthesis of the triblock PLLAPCL-PLLA copolymer was carried out using PCL-OH as initiator and stannous-2-ethylhexanoate as catalyst according to reported procedures [16]. The characterization data are summarized in Table 1.

\subsection{Melt blending}

$2.5 \mathrm{~g}$ of both binary and ternary blends of different composition were prepared under a nitrogen atmosphere in a co-rotating twin-screw batch-type mini-extruder
(DSM) equipped with twin stainless steel screws and a side channel which allows continuous recycling of the material at the head of the mixing chamber. Amount maximum of $4 \mathrm{~g}$ of material may be mixed. The mixing time, temperature and rotor speed were $5 \mathrm{~min}, 200^{\circ} \mathrm{C}$ and $40 \mathrm{rpm}$, respectively. The blends obtained were quenched in liquid nitrogen.

\subsection{Techniques}

SEC was performed by a Jasco PU-1580 instrument equipped with two Polymer Laboratories PL gel MIXEDC5 micron columns and a Jasco 830 RI detector, using chloroform as solvent and polystyrene standards. The SEM analysis, performed using a Philips (XL 20 Model or $501 \mathrm{~B})$ scanning electron microscope, was carried out on extrudate rods fractured in liquid nitrogen which were observed at different magnifications. Moreover, rods of the prepared blends were smoothed by an LKB Ultratone III ultramicrotome and their surface was etched by THF vapours at $50^{\circ} \mathrm{C}$ for $45 \mathrm{~min}$, and afterwards, they were observed by SEM. Several micrographs were taken for each sample. Thin samples between glass-slides were observed by an Olympus optical microscope equipped with a Mettler hot stage. They were heated to $200^{\circ} \mathrm{C}$, cooled to $125^{\circ} \mathrm{C}$ at a rate of $5^{\circ} \mathrm{C} / \mathrm{min}$ and kept at this temperature for $50 \mathrm{~min}$. Thermal analyses of the blends were performed with a Perkin-Elmer 'Pyris' DSC. The blends were first heated at $200^{\circ} \mathrm{C}$ for $2 \mathrm{~min}$ to erase previous thermal history before being rapidly cooled to $50^{\circ} \mathrm{C}$ at a $200^{\circ} \mathrm{C} / \mathrm{min}$ rate. The samples were subsequently scanned at $20^{\circ} \mathrm{C} / \mathrm{min}$ to observe the cold crystallizations. A Mettler DSC was used to obtain crystallization isotherms. Samples were first kept at $200^{\circ} \mathrm{C}$ for $3 \mathrm{~min}$, followed by cooling at $20^{\circ} \mathrm{C} / \mathrm{min}$ to the crystallization temperature of $140^{\circ} \mathrm{C}$. DMTA experiments were performed using a Polymer Laboratories MKIII analyser operating at $1 \mathrm{~Hz}$ on $0.4-0.5 \mathrm{~mm}$ thick films obtained by compression moulding. Image analysis of the PCL domains was performed using Image Pro Plus software. The SEM micrographs of the fracture surface of the samples were digitalized and mathematically manipulated for analysis. The surfaces obtained were studied using 256 grey levels. PCL domains of fairly circular shape, immersed in PLLA matrix, were clearly visible in all the micrographs. Each picture contained between 140 and 500 domains and for each analysis, at least 1000 domains were considered.

Table 1

Characterization data of the PLLA triblock copolymer

\begin{tabular}{llllll}
\hline$M_{\mathrm{n}}$, experimental $^{\mathrm{a}}(\mathrm{kDa})$ & $M_{\mathrm{n}}$, theoretical $^{\mathrm{b}}(\mathrm{kDa})$ & $M_{\mathrm{w}} / M_{\mathrm{n}}{ }^{\mathrm{c}}$ & $\eta_{\text {inh }}{ }^{\mathrm{d}}(\mathrm{dl} / \mathrm{g})$ & $T_{\mathrm{m}}{ }^{\mathrm{e}}\left({ }^{\circ} \mathrm{C}\right)$ & $\Delta H_{\mathrm{m}}{ }^{\mathrm{e}}(\mathrm{J} / \mathrm{g})$ \\
\hline 49.0 & 50.3 & 1.32 & 0.91 & 174 & 38 \\
\hline
\end{tabular}

\footnotetext{
${ }^{a}$ Evaluated from ${ }^{1} \mathrm{H}$ NMR spectra.

b Theoretical values calculated from the feed composition.

${ }^{c}$ Evaluated from SEC.

${ }^{\mathrm{d}}$ Inherent viscosities in $\mathrm{CHCl}_{3}$ at $25^{\circ} \mathrm{C}(c=0.5 \mathrm{~g} / \mathrm{dl})$.

${ }^{\mathrm{e}}$ Evaluated from DSC and relative to PLLA blocks.
} 
Table 2

Blends prepared: composition and code

\begin{tabular}{|c|c|c|c|c|}
\hline Blend & Composition (w/w) & Copolymer added & Copolymer amount (wt\%) & Code \\
\hline PLLA/PCL & $90 / 10$ & - & - & $\mathrm{M}_{1}$ \\
\hline PLLA/PCL & $80 / 20$ & - & - & $\mathrm{M}_{2}$ \\
\hline PLLA/PCL & $70 / 30$ & - & - & $\mathrm{M}_{3}$ \\
\hline PLLA/PCL & $90 / 10$ & PLLA-PCL-PLLA & 5 & $\mathrm{M}_{1}-\mathrm{C}-5$ \\
\hline PLLA/PCL & $80 / 20$ & PLLA-PCL-PLLA & 5 & $\mathrm{M}_{2}-\mathrm{C}-5$ \\
\hline PLLA/PCL & $70 / 30$ & PLLA-PCL-PLLA & 0.5 & $\mathrm{M}_{3}-\mathrm{C}-0.5$ \\
\hline PLLA/PCL & $70 / 30$ & PLLA-PCL-PLLA & 2 & $\mathrm{M}_{3}-\mathrm{C}-2$ \\
\hline PLLA/PCL & $70 / 30$ & PLLA-PCL-PLLA & 5 & $\mathrm{M}_{3}-\mathrm{C}-5$ \\
\hline
\end{tabular}

Greater attention was given to the area values and to the numerical density of these domains on the entire surface of the micrograph.

\section{Results and discussion}

PLLA and PCL, the components of the blends described in the present paper, are reported to be immiscible [5]. Using thermomechanical models, several authors have demonstrated that the morphology of an immiscible polymer blend is strongly dependent on two mechanisms occurring during the mixing, i.e. break-up and coalescence $[11,12]$. To reduce coalescence, which is responsible for phase coarsening, a very efficient corotating twin-screw mini-extruder with a retro-feeding channel system was used in the present research. Thus, a favourable equilibrium state between the break-up and coalescence mechanisms can easily be achieved [9]. During this work, we prepared three binary PLLA/PCL blends of different composition $(70 / 30,80 / 20,90 / 10 \mathrm{wt} \%)$ in which PCL is the dispersed phase, and ternary blends containing, as an emulsifying agent, $0.5-5 \mathrm{wt} \%$ of a triblock PLLA-PCL-PLLA copolymer. The copolymer architecture consists of a central PCL block of average length of $10 \mathrm{KDa}$ and of two PLLA arms of average length of $20 \mathrm{KDa}$. The compositions and the codes of the prepared blends are listed in Table 2.

SEC analysis was carried out on pure PLLA and PCL before and after mixing in order to detect the occurrence of thermomechanical chain scission. The results obtained, reported in Table 3, show that, under our experimental conditions, a moderate decrease in molecular weight was observed only in the case of PLLA. The high molecular weight of both polymers after processing ensures that their

Table 3

SEC analysis of pure PLLA and PCL polymers before and after extrusion (pure PLLA and PCL were extruded at $200^{\circ} \mathrm{C}$ for 5 min under a nitrogen atmosphere)

\begin{tabular}{llcl}
\hline Polymers & $M_{\mathrm{n}}(\mathrm{kDa})$ & $M_{\mathrm{w}}(\mathrm{kDa})$ & $M_{\mathrm{w}} / M_{\mathrm{n}}$ \\
\hline PLLA & 63.4 & 117.3 & 1.8 \\
PLLA extruded & 45.1 & 82.4 & 1.8 \\
PCL & 73.7 & 126.1 & 1.7 \\
PCL extruded & 66.5 & 127.9 & 1.8 \\
\hline
\end{tabular}

bulk properties are not affected by the melt mixing. It has been already shown that thermal degradation and transesterification reactions between the two polyesters do not occur significantly under the mixing conditions used [16].

\subsection{Thermal properties of PLLA/PCL blends}

The influence of PCL on the PLLA crystallization, both from the glassy state and from the melt, was studied by optical microscopy, DSC and DMTA experiments. These techniques also gave useful information on the miscibility between PLLA and PCL. The DSC heating scans from -100 to $200^{\circ} \mathrm{C}$ of the melt-quenched PLLA/PCL blends of different compositions show PLLA cold crystallization exotherms. The thermal parameters obtained are listed in Table 4. A melting endotherm of PCL appears at $57^{\circ} \mathrm{C}$ while there is no evidence of any PCL cold crystallization. In fact, $\mathrm{PCL}$ is an highly flexible polyester able to crystallize during rapid cooling. A cold crystallization exotherm located at $115^{\circ} \mathrm{C}$ is observed for pure PLLA processed in the same conditions of the blends. Although this exotherm is shifted to $100^{\circ} \mathrm{C}$ upon blending with $10 \mathrm{wt} \%$ of PCL, a further increase in PCL composition has no effect on the position of this exotherm. Thus, it would appear that the crystallization of PLLA from the glassy state can be promoted by the addition of PCL as it occurs at a lower temperature with respect to pure PLLA. On the contrary, the PCL presence does not affect the PLLA melting temperature and the slight increase in the $\Delta H_{\mathrm{m}}$ values of PLLA in the blends may be related to an improved perfection of PLLA crystals. In fact, when PLLA is blended to

Table 4

Cold crystallization parameters of PLLA and PLLA/PCL blends (PLLA and blends are all extruded at $200^{\circ} \mathrm{C}$ for $5 \mathrm{~min}$ )

\begin{tabular}{lllll}
\hline PLLA amount $(\mathrm{wt} \%)$ & $T_{\mathrm{c}}{ }^{\mathrm{a}}\left({ }^{\circ} \mathrm{C}\right)$ & $\Delta H_{\mathrm{c}}{ }^{\mathrm{b}}(\mathrm{J} / \mathrm{g})$ & $T_{\mathrm{m}}{ }^{\mathrm{a}}\left({ }^{\circ} \mathrm{C}\right)$ & $\Delta H_{\mathrm{m}}{ }^{\mathrm{a}, \mathrm{c}}(\mathrm{J} / \mathrm{g})$ \\
\hline 100 & 115 & 45 & 179 & 47 \\
90 & 100 & 35 & 178 & 55 \\
80 & 100 & 35 & 179 & 56 \\
70 & 100 & 34 & 177 & 56
\end{tabular}

\footnotetext{
${ }^{\mathrm{a}}$ Evaluated after rapid cooling from the melt followed by heating from -100 to $200^{\circ} \mathrm{C}$ at $20^{\circ} \mathrm{C} / \mathrm{min}$.

${ }^{\mathrm{b}}$ PLLA and blends are all extruded at $200^{\circ} \mathrm{C}$ for $5 \mathrm{~min}$.

${ }^{c}$ Values corrected for blend composition.
} 


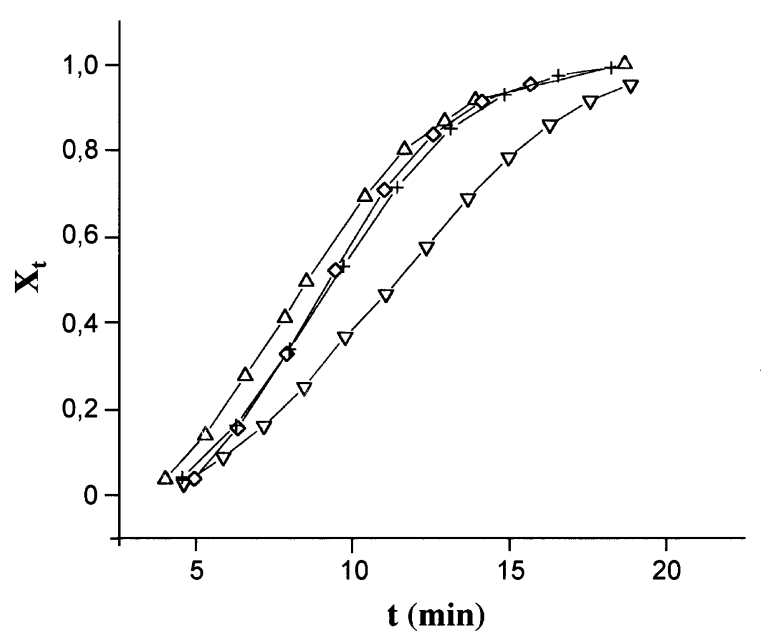

Fig. 1. Crystallization isotherms at $140^{\circ} \mathrm{C}$ of PLLA $(\nabla)$ and PLLA/PCL blends $(90 / 10, \triangle),(80 / 20, \diamond),(70 / 30,+)$.

PCL, reorganization of the polymer chains within the crystalline PLLA phase is favoured by a higher $T_{\mathrm{m}}-T_{\mathrm{c}}$ difference than for the pure homopolymer. It is also important to note that for all the blends, the enthalpy of crystallization during the heating scan is lower than the subsequent enthalpy of melting, while the two values are practically identical for PLLA. This would also suggest that part of PLLA is able to crystallize during the first cycle of blend melt quenching. These findings were checked by analysing melt crystallization behaviour. Fig. 1 shows the profiles of crystallization isotherms at $140^{\circ} \mathrm{C}$ obtained by plotting the amount of crystallized material at time $t\left(X_{t}\right)$ versus time for pure PLLA and PLLA/PCL binary blends. The half time of crystallization $t_{1 / 2}$ was then calculated from these curves. The Avrami exponent $n$ at $140^{\circ} \mathrm{C}$ was obtained from the slope of lines obtained by plotting the quantity $\log [-\log (1-x t)]$ against $\log t$ as shown in Fig. 2. The rate constant $Z$ was calculated according

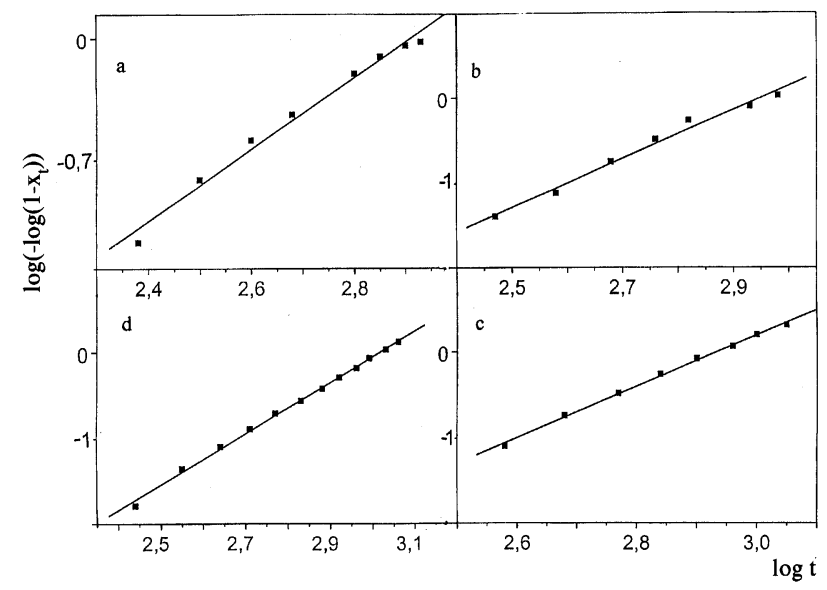

Fig. 2. Avrami plots of PLLA/PCL 90/10 (a), 80/20 (b), 70/30 blends (c) and PLLA (d).
Table 5

Isothermal crystallization parameters of PLLA /PCL blends at $140^{\circ} \mathrm{C}$

\begin{tabular}{lclll}
\hline PLLA (wt\%) & 100 & 90 & 80 & 70 \\
\hline$n^{\mathrm{a}}$ & 3.0 & 2.7 & 3.0 & 3.0 \\
$t_{1 / 2}{ }^{\mathrm{b}}(\min )$ & 12.6 & 8.6 & 9.5 & 9.6 \\
$Z^{\mathrm{c}}\left(\mathrm{min}^{-1}\right)$ & $3.5 \times 10^{-4}$ & $2.1 \times 10^{-3}$ & $8.1 \times 10^{-4}$ & $7.8 \times 10^{-4}$ \\
\hline
\end{tabular}

${ }^{a}$ Avrami exponent.

${ }^{\mathrm{b}}$ Semi-crystallization time.

c Rate constant.

to the relation:

$\mathrm{Z}=\frac{\ln 2}{\left(t_{1 / 2}\right)^{n}}$

The crystallization parameters obtained are reported in Table 5. The PLLA spherulites mechanism of growth does not change when different amounts of PCL are present, since the Avrami exponent values, $n$, are close to 3 for all the materials. This value suggests a tridimensional mechanism of growth in PLLA spherulites with heterogeneous nucleation. However, the presence of PCL domains in the PLLA matrix causes a small, but significant, lowering in $t_{1 / 2}$
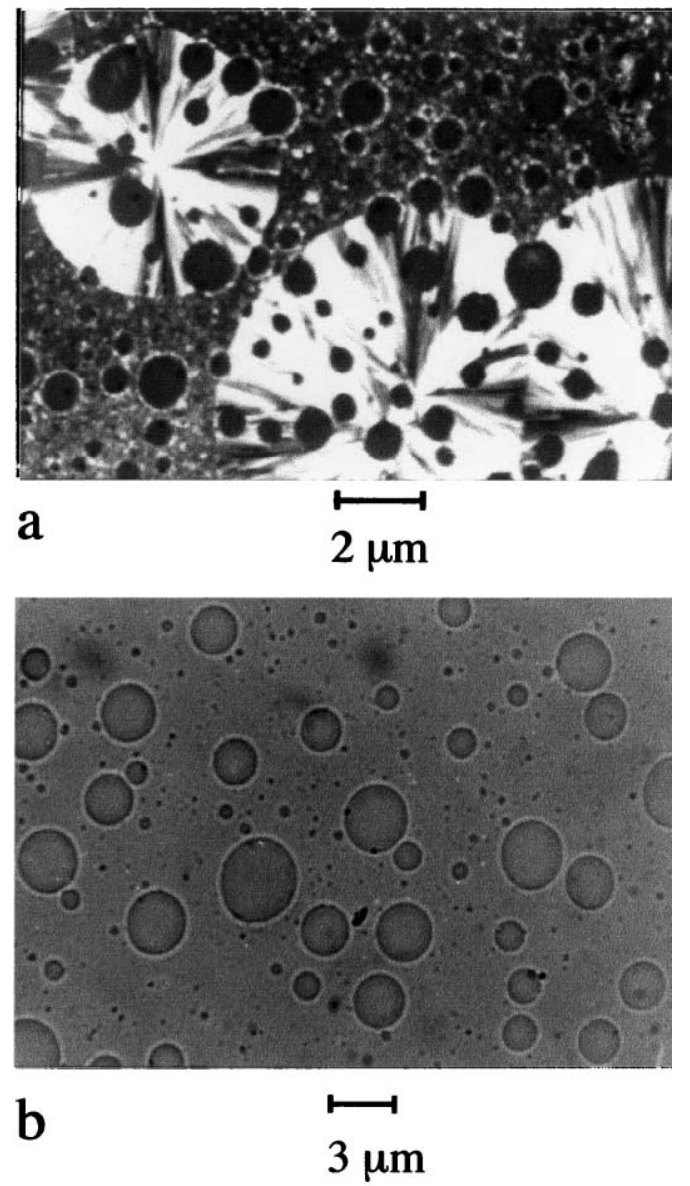

Fig. 3. Optical micrographs of $\mathrm{M}_{2}$ blend at $125^{\circ} \mathrm{C}$ (a) and in the melt state (b). 
Table 6

Glass transition temperatures of PLLA, PCL and their binary blends

\begin{tabular}{rcc}
\hline PLLA $(w t \%)$ & $T_{\mathrm{g}}{ }^{\mathrm{a}}\left({ }^{\circ} \mathrm{C}\right)$ & \\
\cline { 2 - 3 } & PLLA & PCL \\
\hline 0 & - & -36.8 \\
100 & 70.1 & - \\
90 & 71.1 & -37.5 \\
80 & 72.2 & -36.6 \\
70 & 71.8 & -37.2 \\
\hline
\end{tabular}

a Evaluated from DMTA.

values. The rate constant $Z$ of PLLA, evaluated at $140^{\circ} \mathrm{C}$, increases correspondingly upon blending with $10 \mathrm{wt} \%$ of PCL, while a further increase in PCL content keeps the $Z$ value almost constant. These results indicate that the PCL presence enhances the PLLA crystallization rate, as suggested by the dynamic experiments, and this likely occurs through the increase in the nucleation rate. However, the lowering of the $t_{1 / 2}$ value is independent from the amount of PCL. This finding may be related to the immiscibility of the blends components. In fact, the interface of the phaseseparated domains may provide favourable nucleation sites for crystallization and, therefore, the crystallization rate of PLLA is promoted by a nucleation barrier lower than that of pure PLLA melt. Optical micrographs of $\mathrm{M}_{3}$ blends quenched from $125^{\circ} \mathrm{C}$ to room temperature (Fig. 3) show that a phase separation in PLLA/PCL blends occurs in the melt and that at $125^{\circ} \mathrm{C}$ PLLA crystallizes preferentially around molten PCL domains. In order to confirm these observations, DMTA experiments were performed and the glass transition temperatures of pure PLLA and PCL extrudates as well as of their blends, were evaluated. The $T_{\mathrm{g}}$ values observed are reported in Table 6 . The presence in the DMTA spectra of two glass transition temperatures which were very close to those found for pure PLLA and PCL confirms that the two polyesters are immiscible.

The thermal properties of the blends were also investigated when different amounts of a PLLA-PCL-PLLA copolymer were added to the PLLA/PCL mixtures. Tables 7 and 8 report the results of cold crystallization and DMTA experiments, respectively, obtained in the case of ternary blends containing $5 \mathrm{wt} \%$ of the triblock copolymer. No significant changes in $T_{\mathrm{g}}, T_{\mathrm{c}}, T_{\mathrm{m}}$ and

Table 7

Cold crystallization parameters of ternary PLLA/PCL/PLLA-PCL-PLLA blends (blends were extruded at $200^{\circ} \mathrm{C}$ for $5 \mathrm{~min}$ )

\begin{tabular}{lclll}
\hline Blends & $T_{\mathrm{c}}{ }^{\mathrm{a}}\left({ }^{\circ} \mathrm{C}\right)$ & $\Delta H_{\mathrm{c}}^{\mathrm{a}, \mathrm{b}}(\mathrm{J} / \mathrm{g})$ & $T_{\mathrm{m}}{ }^{\mathrm{a}}\left({ }^{\circ} \mathrm{C}\right)$ & $\Delta H_{\mathrm{m}}{ }^{\mathrm{a}, \mathrm{b}}(\mathrm{J} / \mathrm{g})$ \\
\hline $\mathrm{M}_{1}-\mathrm{C}-5$ & 99 & 35 & 179 & 55 \\
$\mathrm{M}_{2}-\mathrm{C}-5$ & 100 & 35 & 178 & 56 \\
$\mathrm{M}_{3}-\mathrm{C}-5$ & 100 & 35 & 179 & 56 \\
\hline
\end{tabular}

${ }^{a}$ Evaluated after rapid cooling from the melt followed by heating from -100 to $200^{\circ} \mathrm{C}$ at $20^{\circ} \mathrm{C} / \mathrm{min}$.

b Values corrected for blend composition.
Table 8

Glass transition temperatures of ternary PLLA/PCL/PLLA-PCL-PLLA blends

\begin{tabular}{lll}
\hline Blends & \multicolumn{2}{c}{$T_{\mathrm{g}}{ }^{\mathrm{a}}\left({ }^{\circ} \mathrm{C}\right)$} \\
\cline { 2 - 3 } & PLLA & PCL \\
\hline $\mathrm{M}_{1}-\mathrm{C}-5$ & 71.8 & -37.2 \\
$\mathrm{M}_{2}-\mathrm{C}-5$ & 72.4 & -35.7 \\
$\mathrm{M}_{3}-\mathrm{C}-5$ & 72.2 & -36.6 \\
\hline
\end{tabular}

a Obtained from DMTA spectra.

$\Delta H_{\mathrm{m}}$ values were observed. Moreover, the crystallization curves obtained for $\mathrm{M}_{1}-\mathrm{C}-5, \mathrm{M}_{2}-\mathrm{C}-5$ and $\mathrm{M}_{3}-\mathrm{C}-5$ blends are almost superimposable with those of the corresponding binary blends and, again, they yielded $n$ values close to 3 . It is therefore clear that the copolymer
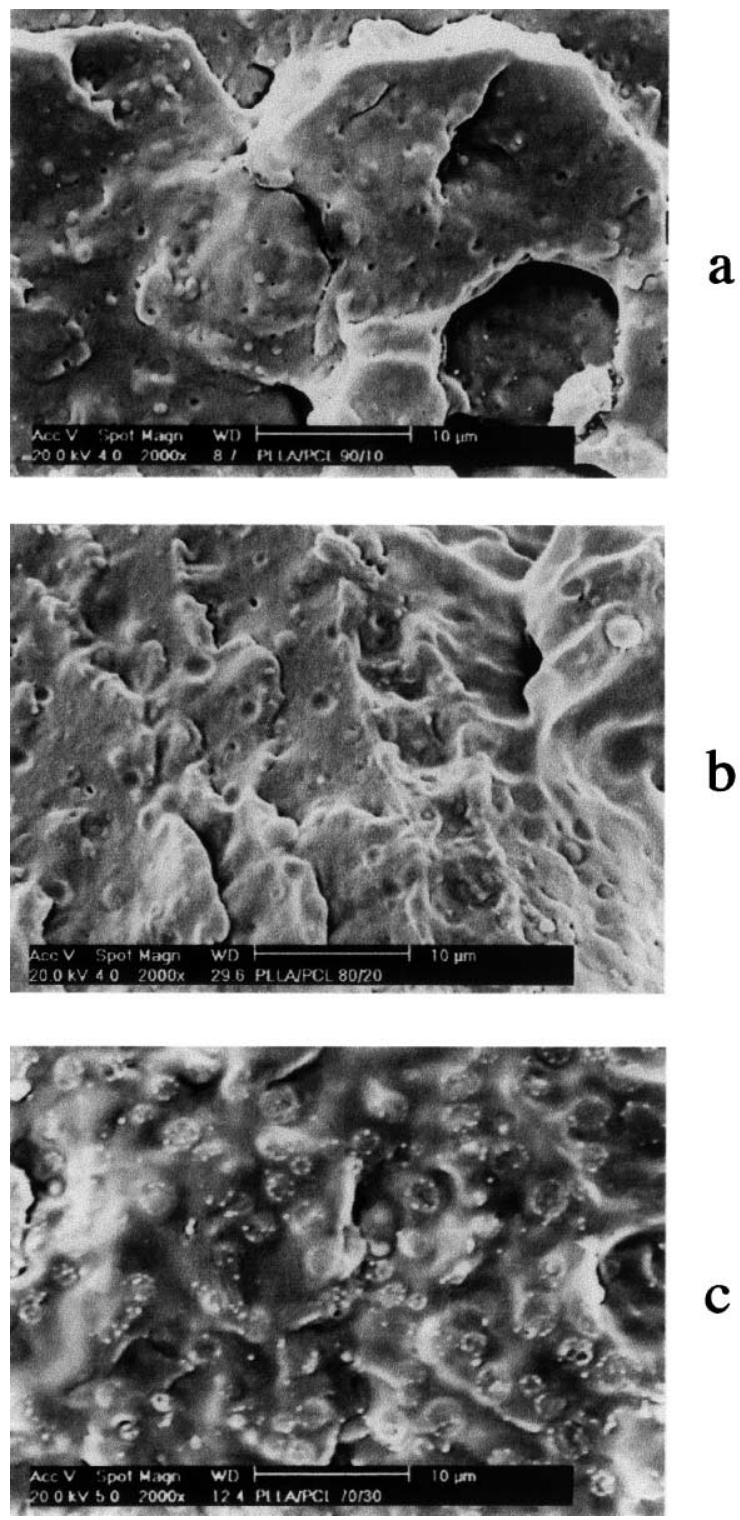

Fig. 4. SEM micrographs of cryofractured surfaces of binary $M_{1}(a), M_{2}$ (b), $\mathrm{M}_{3}$ (c) blends. 
presence does not significantly affect the PLLA crystallization kinetics and mechanism. As a matter of fact, the addition of a copolymer to a blend of immiscible polymers, particularly for the low contents herein described, may influence the state of dispersion of the two polymers by reducing the interfacial tension while does not necessarily affect bulk properties, such as crystallization behaviour or glass transitions [10-17].

\subsection{Morphological analysis of PLLA/PCL binary blends}

The morphological analysis of binary PLLA/PCL mixtures was performed by first studying morphology

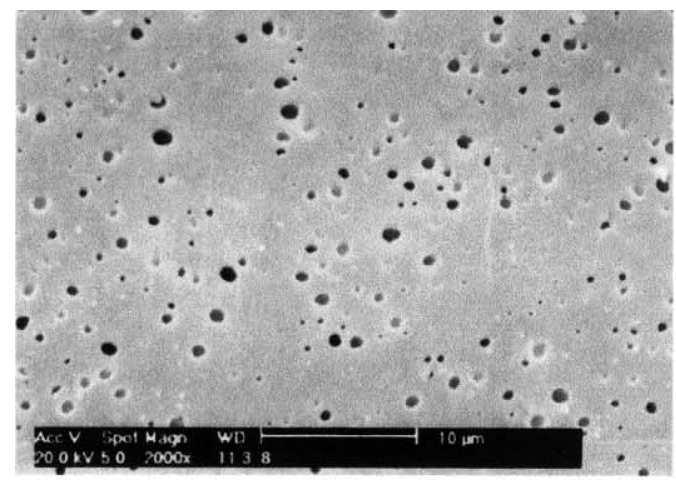

a

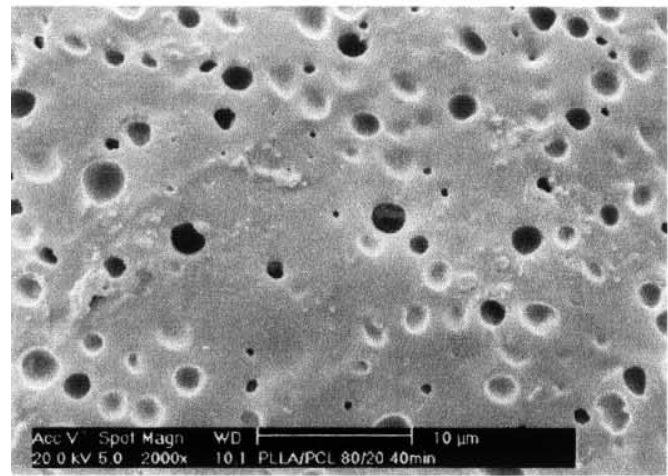

b

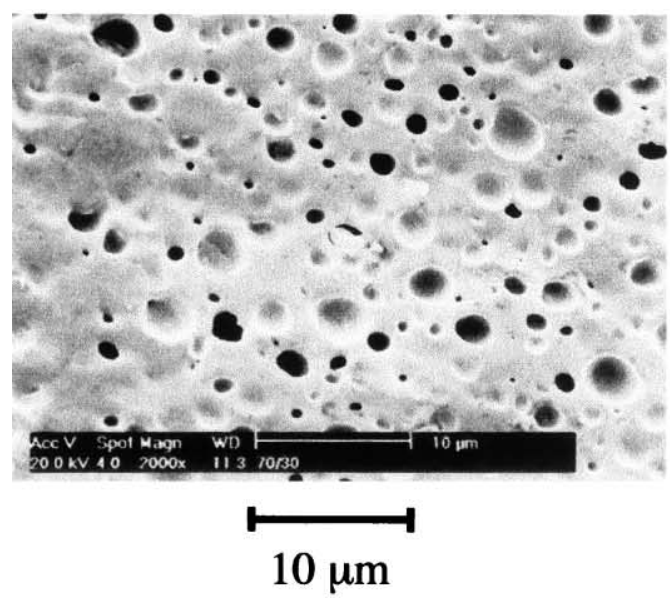

c

Fig. 5. SEM micrographs of smoothed and etched surfaces of binary blends $M_{1}$ (a), $M_{2}$ (b) and $M_{3}$ (c). dependence on the composition of the blends. Figs. 4 and 5 show SEM micrographs of cryofractured, smoothed and etched surfaces of binary $\mathrm{M}_{1}, \mathrm{M}_{2}$ and $\mathrm{M}_{3}$ blends, respectively. They indicate fine blend morphologies with dispersed phase domains which are spherical in shape. The particle size increases as the dispersed-phase concentration increases because of coalescence phenomena. This is particularly evident when comparing blends with 10$20 \mathrm{wt} \%$ PCL content. The coalescence phenomenon of the minor phase in the melt strongly influences the polymer blends morphology and is very important since blends are often annealed during the manufacturing process. Several authors relate the effect of coalescence to the droplet agglomeration during melt mixing, which is a random process [8-10]. In particular, coalescence coarsening is reported to be highly dependent on the minor phase concentration [9]. Accordingly, the extent of coalescence in the binary PLLA/PCL polymer blends increases significantly as the concentration of the dispersed phase increases. Moreover, the micrograph of the cryofractured surface of $\mathrm{M}_{3}$ blend (Fig. 5c) shows a 'shell-core' morphology where dispersed phase domains sub-include matrix domains, indicating a good interpenetration between the blends components. It is well known that binary polymer blends of immiscible components usually present a very coarse

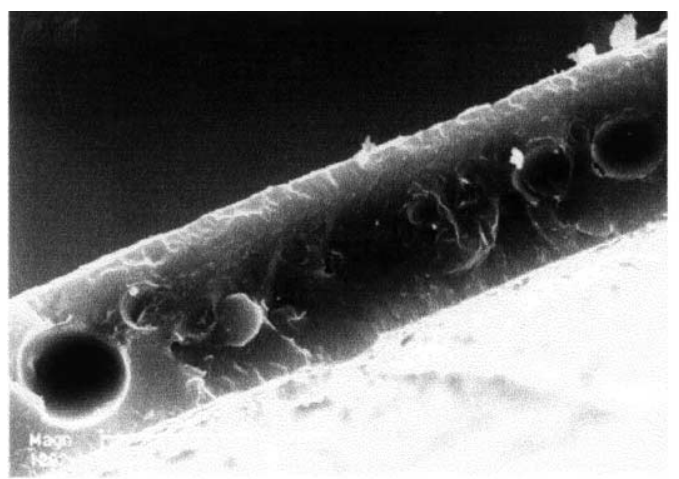

$\mathbf{a}$

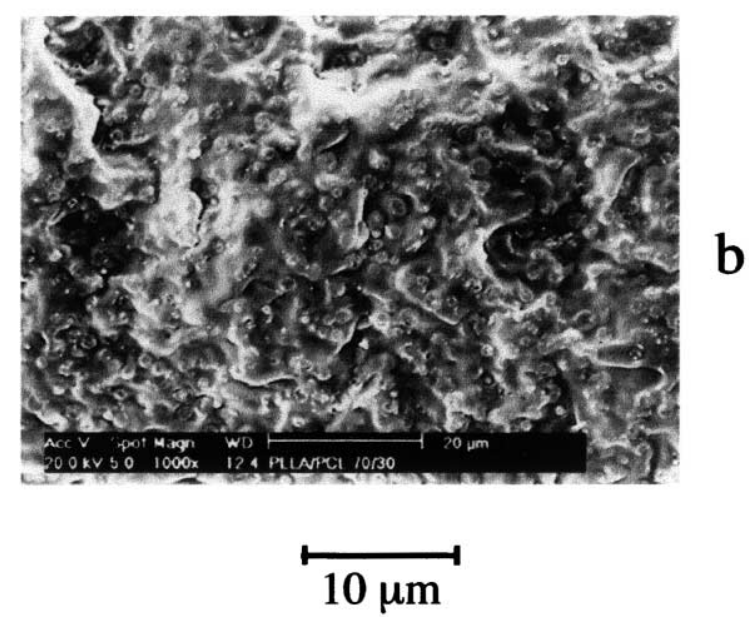

Fig. 6. Cryofractured surfaces of $\mathrm{M}_{3}^{0}$ (a) and $\mathrm{M}_{3}$ (b) binary blends. 
morphology with a sharp interface, as in the case of blends of components with very different solubility parameters and with no specific interactions (e.g. a thermoplastic/elastomeric polymer couple such as polyamide/polyolefin blends [18]). Given this, the observed shell-core morphology of binary immiscible PLLA/PCL blends requires some further comments. We can attempt an explanation on the basis of two important factors that exert a significant influence on the morphology of the investigated blends, the chemical nature of the components and the characteristics of the mixer used. Regarding the chemical nature, PLLA and PCL are both semicrystalline aliphatic polyesters with a fairly close thermal expansion coefficients and a difference in solubility parameter of less than one [19]. On this basis, it is reasonable to assume that low interfacial tensions are obtained in binary PLLA/PCL blends because of the similar chemical nature of the blends components, which allows interpolymer polar interactions across phase boundaries, thus favouring a well-dispersed morphology. Moreover, when a very efficient twin screw extruder is used to mix an 'oil in oil emulsion' system such as that PLLA/PCL, the 'break-up' of the dispersed phase in very small particles occurs easily because of high shear deformations and strong stresses on the melt. Additional evidence proving the importance of the efficiency of the mixer on the system PLLA/ PCL is shown in Fig. 6 where a comparison is made of the different morphologies found for 70/30 blends obtained using a single screw extruder $\left(\mathbf{M}_{3}^{0}\right.$, a) [16] or the twin screw extruder employed in the present paper $\left(\mathrm{M}_{3}, \mathrm{~b}\right)$. It is evident how the low shear forces applied on the melt lead to a very coarse final blend morphology with dispersed phase dimensions one order of magnitude higher than those obtained in the case of the twin extruder.

\subsection{Morphological analysis of PLLA/PCL/PLLA-PCL- PLLA ternary blends}

The PLLA-PCL-PLLA triblock copolymer was added to PLLA/PCL blends as an emulsifying agent and the morphology of the ternary blends was studied, particularly in the case of the 70/30 PLLA/PCL composition characterized by a coarser morphology. Fig. 7 shows SEM micrographs of smoothed and etched surfaces of binary $\mathrm{M}_{3}$ blends and $\mathrm{M}_{3}-$ C-0.5, $\mathrm{M}_{3}-\mathrm{C}-2$ and $\mathrm{M}_{3}-\mathrm{C}-5$ ternary blends (see Table 9). The emulsifying effect of the copolymer is clearly observed. It is worth noting that the morphology observed in the mixture containing $2 \mathrm{wt} \%$ of copolymer does not change upon the further addition of copolymer up to $5 \mathrm{wt} \%$. The highest reduction in PCL particle size was already achieved in the case of the $\mathrm{M}_{3}-\mathrm{C}-2$ blend. The excess copolymer present in the $\mathrm{M}_{3}-\mathrm{C}-5$ blend should probably constitute its
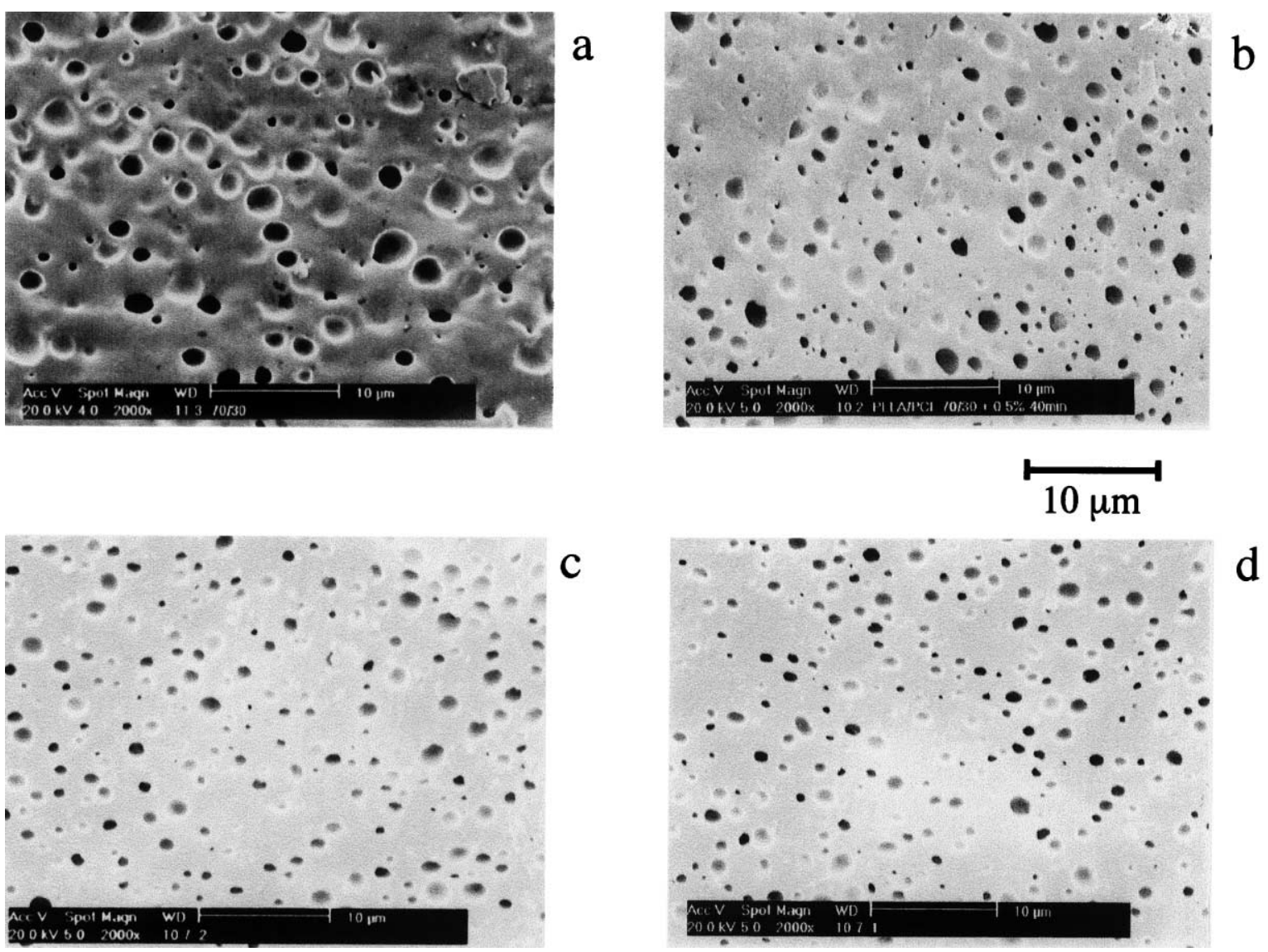

Fig. 7. Smoothed and etched surfaces of $\mathrm{M}_{3}$ (a), $\mathrm{M}_{3}-\mathrm{C}-0.5$ (b), $\mathrm{M}_{3}-\mathrm{C}-2$ (c) and $\mathrm{M}_{3}-\mathrm{C}-5$ (d) blends. 
Table 9

Surface measurements of PLLA/PCL binary blends and PLLA/PCL 70/30 ternary blends with varying amounts of copolymer

\begin{tabular}{|c|c|c|c|c|c|c|c|}
\hline Blend & $S_{\mathrm{av}}^{\mathrm{a}}\left(\mu \mathrm{m}^{2}\right)$ & $\sigma^{\mathrm{b}}\left(\mu \mathrm{m}^{2}\right)$ & $S_{\max }{ }^{\mathrm{c}}\left(\mu \mathrm{m}^{2}\right)$ & Class $^{\mathrm{d}} 1(\mathrm{~S} \%)$ & Class $^{\mathrm{d}} 2(\mathrm{~S} \%)$ & Class $^{\mathrm{d}} 1(\mathrm{~N} \%)$ & Class $^{\mathrm{d}} 2(\mathrm{~N} \%)$ \\
\hline $\mathrm{M}_{1}$ & 0.21 & 0.22 & 1.19 & 27 & 73 & 65 & 35 \\
\hline $\mathrm{M}_{2}$ & 0.66 & 0.67 & 3.67 & 24 & 76 & 62 & 38 \\
\hline $\mathrm{M}_{3}$ & 0.85 & 1.02 & 7.38 & 23 & 77 & 63 & 37 \\
\hline $\mathrm{M}_{3} \mathrm{C}-0.5$ & 0.48 & 0.58 & 3.63 & 22 & 78 & 67 & 33 \\
\hline $\mathrm{M}_{3}-\mathrm{C}-2$ & 0.45 & 0.40 & 2.25 & 26 & 74 & 61 & 39 \\
\hline$M_{3}-C-5$ & 0.44 & 0.39 & 2.24 & 25 & 75 & 61 & 39 \\
\hline
\end{tabular}

a Average area of domains.

b Standard deviation.

c Maximum area.

d Small domains (class 1) and large domains (class 2).

own domains (micelle formation) in the matrix polymer, due to saturation of the interface.

\subsection{Micrograph image analysis}

The image analysis was performed on SEM micrographs of the smoothed and etched surfaces of the samples $\mathrm{M}_{1}, \mathrm{M}_{2}$, $\mathrm{M}_{3}$ and $\mathrm{M}_{3}-\mathrm{C}-0.5, \mathrm{M}_{3}-\mathrm{C}-2$ and $\mathrm{M}_{3}-\mathrm{C}-5$. The results obtained are reported in Table 9. The first three columns of the table show the average area of domains, $S$, the standard deviation, $\sigma$, and the dimensions of the maximum area detected, $S_{\max }$. From this analysis, the following conclusions can be drawn. Firstly, the area of the PCL domains decreases by decreasing the PCL content (see samples $\mathrm{M}_{1}$, $\mathrm{M}_{2}$ and $\mathrm{M}_{3}$ ). This fact can be explained if we consider that the blend PLLA/PCL is immiscible in all compositions, but not highly incompatible. Thus, the driving force toward demixing is not strong when compared to the shear forces that lead to dispersion. In such a hypothesis, lowering the
PCL content causes two effects which both favour a reduction in domain size, i.e. the volume ratio of the PLLA matrix phase increases, thus increasing shear forces on a single PCL domain, and the probability of coalescence of two separate domains of PCL decreases. Secondly, the addition of the copolymer to the PLLA/PCL blend of composition $70 / 30 \mathrm{wt} \%$ influences the blend morphology. In fact, even at very low copolymer content, a reduction in the PCL domains area is observed for the ternary blends with respect to the $\mathrm{M}_{3}$ blend (compare samples $\mathrm{M}_{3}, \mathrm{M}_{3}-\mathrm{C}-0.5, \mathrm{M}_{3}-\mathrm{C}-2$, $\mathrm{M}_{3}-\mathrm{C}-5$ in Table 9). The increase in the amount of copolymer from $\mathrm{M}_{3}-\mathrm{C}-0.5$ to $\mathrm{M}_{3}-\mathrm{C}-2$ and $\mathrm{M}_{3}-\mathrm{C}-5$ does not lead to any further reduction in the domains area, while a reduction in the standard deviation and $S_{\max }$ values was observed. This indicates that the area reduction of the PCL dispersed particles induced by the presence of the copolymer rapidly reaches a plateau while the introduction of an increasing amount of copolymer allows a more homogeneous distribution of domain dimension, i.e. it is more difficult to find

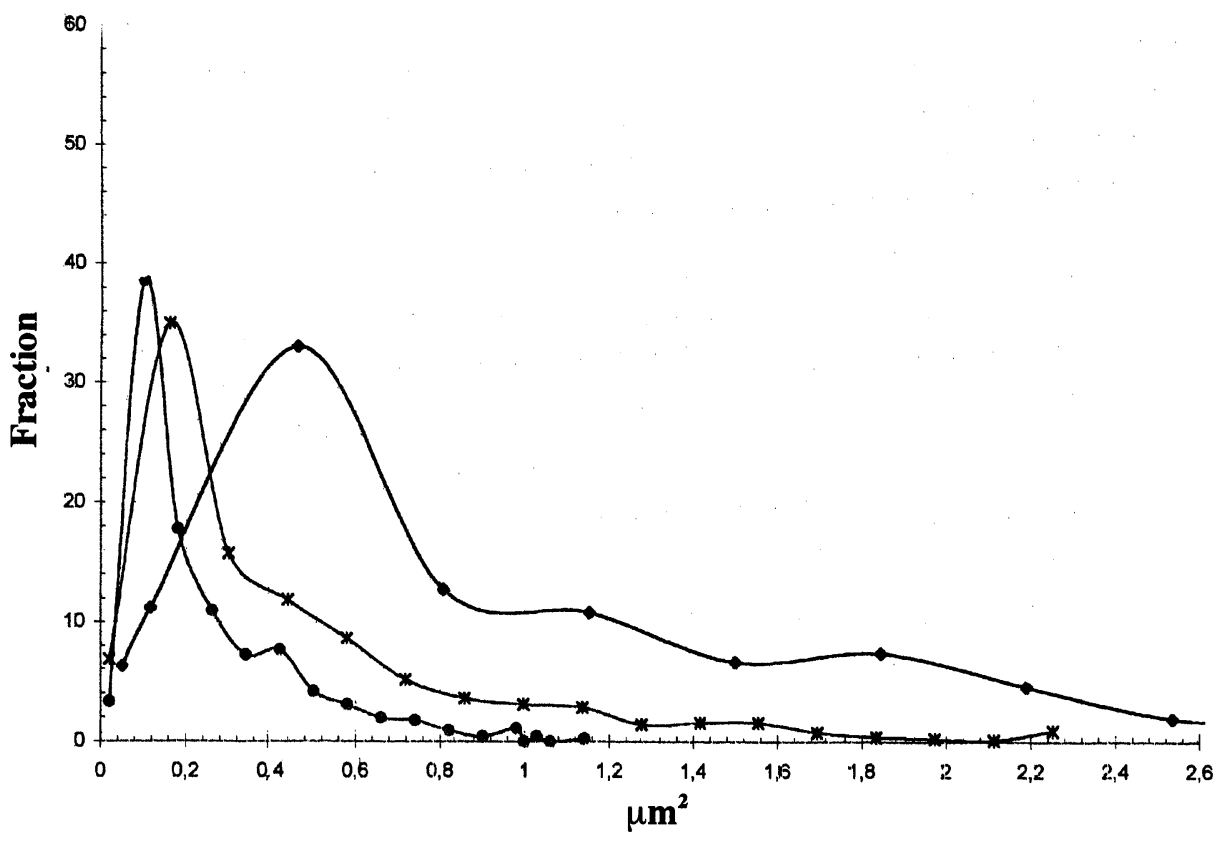

Fig. 8. Distribution curves of area domains of binary $M_{1}(\bullet), M_{2}(*), M_{3}(\bullet)$ blends. 


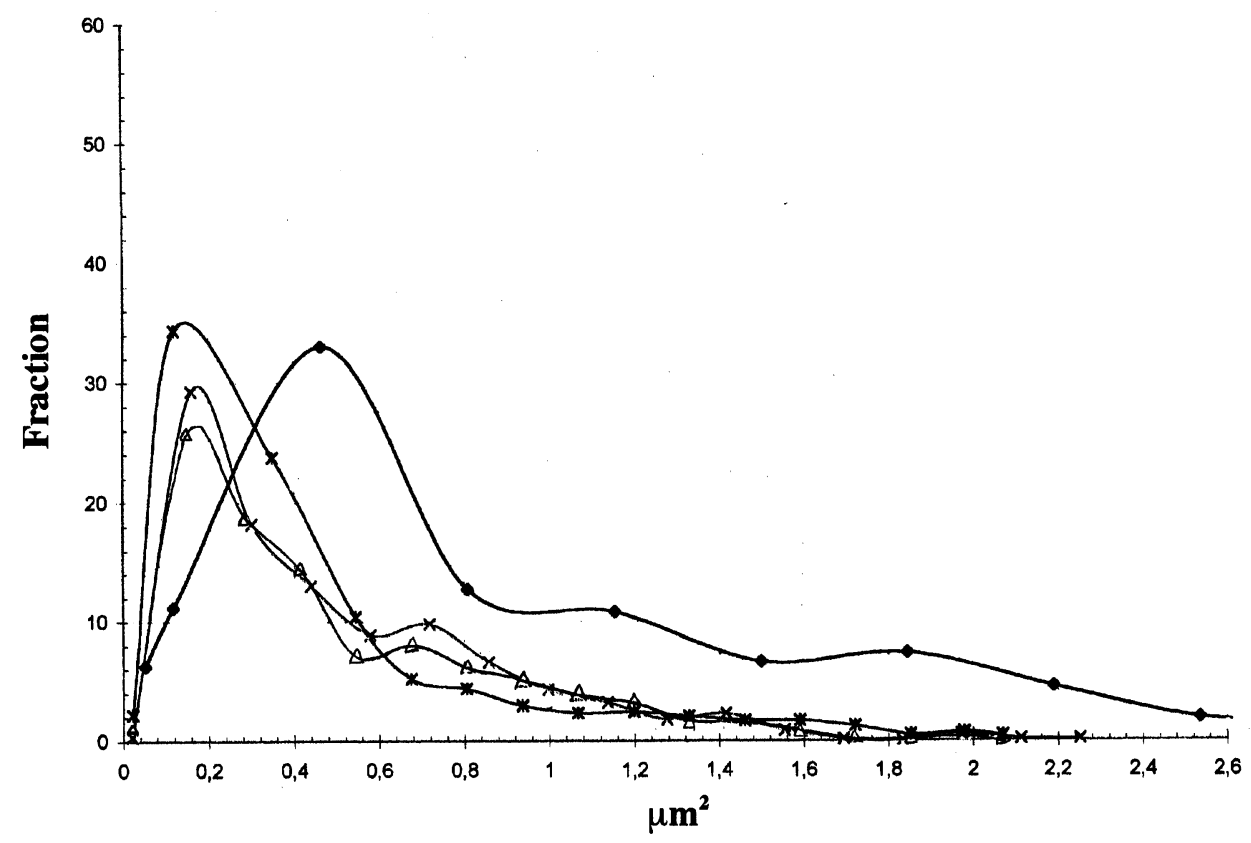

Fig. 9. Distribution curves of area domains of 70/30 PLLA/PCL binary

) and ternary $\mathrm{M}_{3}-\mathrm{C}-0.5(*), \mathrm{M}_{3}-\mathrm{C}-2(\triangle)$ and $\mathrm{M}_{3}-\mathrm{C}-5(\times)$ blends.

'larger' PCL domains. Figs. 8 and 9 show the curves related to the distribution of the area domains in the cases of the binary and ternary blends, respectively. The shape of the curves is the same for all samples. It is noteworthy that there is a strong reduction in width of the curves as the amount of PCL decreases and the copolymer content increases, thus in agreement with the data reported in Table 9. It is also possible to try to analyse the data in terms of the influence of the composition on domain size distribution. We can arbitrarily split the domains into two classes: 'small' domains (areas less than the average values) and 'large' domains (areas greater than the average values). In the last four columns of Table 9, the surface occupied by the two classes and the numerical density values of the domains are reported. From these data we can conclude that small domains are about $63 \% \pm 3$ of the total number of the domains, and they occupy $25 \% \pm 4$ of the detected PCL surface. It is very interesting to note that these values are quite similar for all the samples, indicating (according to the curves shown in Figs. 8 and 9) that by varying both the PCL content or the copolymer content, the trend of the domains distribution is not changed at fixed PLLA/PCL composition.

\section{Conclusions}

Immiscible PLLA/PCL blends characterized by a fine dispersion of PCL domains can be obtained up to a $30 \mathrm{wt} \%$ of PCL by means of high efficiency melt mixing. In addition, morphological and image analysis confirm that, even though PLLA and PCL are immiscible, they are not highly incompatible. The PLLA crystallization rate, both from the melt or the glassy state, was enhanced by the presence of PCL domains, most likely because of the increase in nucleation rate. A more homogeneous distribution of particle size and a lowering of the fraction of large domains was achieved adding small amounts of an emulsifying triblock PLLA-PCL-PLLA copolymer which acts at the phase boundary as an interfacial agent. In such systems, the emulsifier exerts a limited influence on domain size and distribution. Instead, it increases the speed of achievement of the equilibrium conditions, characterized by an intimate dispersion of the blend components.

\section{Acknowledgements}

The financial support from MURST (PRIN 2000) is gratefully acknowledged.

\section{References}

[1] Paul DR, Newman S. Polymer blends, vols. 1 and 2. New York: Academic Press, 1978. p. 390.

[2] Utracki LA. Polymer alloys and blends. Munich: Hanser, 1989.

[3] Pulapura S, Kohn J. J Biomed Appl 1992;6:216.

[4] Deng XM, Xiong CD, Cheng LM, Huang HH, Xu RP. J Appl Polym Sci 1995;55:1193.

[5] Zhu Z, Xiong C, Zhang L, Deng X. J. Polym Sci, Part A: Polym Chem 1997;35:709.

[6] Hiljanen M, Vaino, Varpomaa P, Seppala J, Tormala P. Macromol Chem Phys 1996;197:1503.

[7] Yang JM, Chen HL, You JW, Hwang JC. Polym J 1997;29:657.

[8] Martuscelli E, Palumbo R, Kryszewski M, editors. Polymer blends: processing, morphology and properties. New York: Plenum Press, 1979.

[9] Thomas S, Groeninckx G. J Appl Polym Sci 1999;71:1405. 
[10] Paul DR. In: Paul DR, Newman S, editors. Polymer blends, vol. 2. New York: Academic Press, 1980. p. 35.

[11] Xanthos M. Polym Engng Sci 1988;28:1392.

[12] Porter RS, Janza JM, Kimura M, Desper CR, George ER. Polym Engng Sci 1989;29:55.

[13] Liang HJ, Jow H, Kim J. Macromolecules 1999;32:8204.

[14] Liang HJ. Macromolecules 1997;29:6933.
[15] Zhou Y, Marplus MJ. Chem Phys 1997;107:10691.

[16] Maglio G, Migliozzi A, Palumbo R, Immirzi B, Volpe MG. Macromol Rapid Commun 1999;20:1.

[17] Willis JM, Favis BD. Polym Engng Sci 1984;29:567.

[18] Vanhee S, Koningsveld R, Berghmans H. Macromolecules 2000;33:3924.

[19] Park TG, Cohen S, Langer R. Macromolecules 1992;25:116. 